\title{
NOTES
}

\section{A TWO-ZONE ROOT SYSTEM FOR NUTRIENT UPTAKE STUDIES ${ }^{1}$}

$S^{\mathrm{s}}$ TANFORD and DeMent ${ }^{2}$ recently described an ingenious and useful procedure permitting measurement of shortterm P absorption from soils by attached roots of such species as oats, corn, wheat, or millet. P-deficient plants are grown in sand in nested cartons, the upper of which is bottomless. Nutrients other than $\mathrm{P}$ are applied to the sand in solution. After 2 to 3 weeks the outer carton is removed and the dense mat of roots exposed is brought into contact with a shallow layer of the soil under test. Uptake of $\mathbf{P}$ is determined by analysis of roots and tops after a contact period of several days. This method is clearly capable of modification for a variety of purposes and lends itself to precise control.

In nutrient uptake studies much use has been made of excised roots. There has been no hesitation in regarding these as normal, even though the water relationships of excised root systems must be greatly different from roots attached to a transpiring plant. Uptake experiments with excised roots can only be of short duration because after a few hours high bacterial numbers are found in such cultures.

For some time we have been concerned with root growth and nutrient uptake as affected by ion combinations or the presence of inhibitors, antibiotics, and anti-metabolites. In these we have felt the need for a simple and reproducible system capable of easy experimental manipulation, and without the shortcomings of excised roots. This we have now found in a modification of the Stanford-DeMent method.

Nonabsorbent tapered cartons of approximately 16ounce capacity (such as Dixie Pac cup No. 2186, top diameter $11.5 \mathrm{~cm}$., bottom diameter $9.5 \mathrm{~cm}$., height, $8 \mathrm{~cm}$.) are employed. The bottoms are cut out so that a peripheral annular ring of about $1 \mathrm{~cm}$. remains. A circle of Saran screen cloth, 12 mesh or larger, is placed over the opening and held in place by Duco cement. The growth medium is vermiculite reinforced by such exchange resins and/or clays as may be necessary to secure normal seedling growth, or as may be called for by the requirements of the experiment. In some work the vermiculite instead may be wetted with nutrient solution, or with some compound, the effects of which on growth are under study. The depth of the vermiculite medium is adjusted in relation to the species planted, but a shallow layer is all that is required. For example, for wheat, barley, cress, or flax, all of which have been found to be useful, we first place on the screen a layer of $2.5 \mathrm{~g}$. of vermiculite which is previously sieved to be larger than the mesh of the Saran cloth. This is moistened and followed with $10 \mathrm{~g}$. of vermiculite containing the necessary resins and clays. After moistening overnight, the seed is spread on this surface and covered with another 5-g. layer of vermiculite. The total water-holding capacity of this system is in excess of $50 \mathrm{ml}$. Water can be replaced without drainage if applied in a gentle spray. The whole container is placed on a petri plate containing a few milliliters of water to provide a humid atmosphere under the Saran screen cloth. Roots emerge from the screen after the second day, at which time the petri plate is replaced by a rigid plastic container 4 inches in diameter by $2 y_{2}^{\prime}$ inches high. This has a volume of approximately $400 \mathrm{ml}$. and is

\footnotetext{
${ }^{1}$ Paper No. 17 from the Plant Nutrition Laboratory, The University of Michigan. Received Oct. 31, 1958. Approved Nov. 17, 1958.

${ }^{2}$ Stanford, G., and DeMent, I. D. A method for measuring short-term nutrient absorption by plants: I. Phosphorus. Soil Sci. Soc. Am. Proc. 21:612-617, 1957.
}

almost filled with $1 \times 10^{-4} M \mathrm{CaSO}_{4}$ or with distilled water to which a small quantity of $\mathrm{Ca}$-saturated Amberlite resin IRC-50 is added. We have found this supplementary Ca supply important in the development of normal roots, but in circumstances in which $\mathrm{Ca}$ itself is the nutrient under study, it may be omitted.

After several days, by which time the mass of roots in the lower container is considerable, the plants are ready for treatment. There are various possibilities, depending on the nature of the experiment. The lower container may be replaced by another, preferably of smaller volume, in which the roots are exposed to a salt solution for uptake, or a salt solution plus inhibitor, or an isotopically enriched solution. The uptake period may be brief or many days, if preferred. Comparisons of uptake by excised and attached roots of equal age and similar nutrient regimes are possible. Analysis of the tops allows conclusions to be reached as to the transport of the nutrient under study. The environment with respect to light, temperature, or moisture stress can be modified during the treatment period.

This system is currently in use in studies having diverse objectives, and may be modified in a number of ways. Basically, however, it provides standard roots for uptake studies, the roots themselves not having been fully exposed to the nutrient environment supporting the growth of the seedling.-A. G. NoRman, Professor, The University of Michigan, Ann Arbor; W. A. JACKson, Assistant Professor, North Carolina State College, Raleigh; and Elvera B. ShappInIo, Assistant, Phoenix Project 109, The University of Michigan, Ann Arbor.

\section{INFLUENCE OF TEMPERATURE ON SOIL MOISTURE NEUTRON PROBES ${ }^{1}$}

0 NE OF THE ACCEPTED ADVANTAGES of measuring soil moisture by the neutron method is that this method is assumed to be temperature independent. However, it has been found that erroneous measurements may be taken owing to the effect of temperature on electrical components in the preamplifier of the probe. At present most preamplifier units utilize transistors in the neutron probe for minimizing weight and bulk; however, these transistors are dependent upon external temperatures. In this study two neutron probes ${ }^{2}$ were tested over a range of controlled temperatures.

The probes were inserted into an access tube placed in a constant-temperature bath (2-foot cube) whose temperature was changed $1^{\circ} \mathrm{C}$. every 40 minutes. The 40 -minute interval was found to be adequate for thermal equilibrium before taking a 3-minute count. Probe 1 shows very little temperature dependence below $32^{\circ}$ C. $\left(89.6^{\circ}\right.$ F.) $( \pm 500$ counts per minute in $31,300 \mathrm{cpm}$ ), but as the temperature was increased to $46^{\circ} \mathrm{C}$. the counts per minute reduced to zero as shown by curve 1 (figure 1). At temperatures below $60^{\circ} \mathrm{C}$. $\left(140^{\circ} \mathrm{F}\right.$. $)$ the count rate of probe 2 was $30,500 \pm$ $500 \mathrm{cpm}$. (curve 2, figure 1). The transistors in probe 2 will fail and permanently lose their electrical properties if operated or stored at temperatures exceeding $65.5^{\circ} \mathrm{C}$. $\left(150^{\circ}\right.$ F.).

${ }^{1}$ Contribution from the Department of Irrigation, University of California, Davis. Received Nov. 8, 1958. Approved Jan. 15, 1959.

${ }^{2}$ Both probes were manufactured by Nuclear-Chicago Corp., Chicago, Illinois, Model P.19. Probe 1 contained the preamplifier circuit presently being used by most soils investigators and probe 2 the redesigned circuit now being made by NuclearChicago. 